\title{
Comparison between nurses' and families' opinion about priorities of immediate patient's family needs
}

\author{
Intessar Mohamed Ahmad* \\ Critical Care Nursing Department, Faculty of Nursing, Damanhour University, Damanhour, Egypt
}

Received: July 9, 2018

Accepted: August 28, 2018

Online Published: September 25, 2018

DOI: $10.5430 /$ jnep.v9n1p113

URL: https://doi.org/10.5430/jnep.v9n1p113

\begin{abstract}
Background and objective: Acute critical illness represents a crisis not just for the individual patient however conjointly for the members of the family. Moreover, the admission of the patient represents a sudden crisis allowing no time for its preparation. The responsibilities of critical care nurses extend beyond the patients in the intensive care unit (ICU) to incorporate the members of the family of these patients. Nurses are a primary resource for members of family of ICU patients and they are in a perfect position to assist patients' members of the family in an applicable approach. For this reason, recognition of these needs by nursing personnel is very important for applying of holistic nursing care. The aims of this study were 1) Ranking the immediate needs of members of family of critically ill patients and nurses. 2) Comparing between nurses, and families, opinion regarding priorities of immediate patient's family needs using Critical Care Family Needs Inventory (CCFNI).

Methods: This descriptive study was conducted at the general ICUs of Damanhour Medical Institute which has 15 beds, Damanhour chest hospital which has 7 beds and Itay Elbaroad General Hospital which has 11 beds. The three units have a total of 100 nurses. A questionnaire was used for data collection. It consisted of part one which comprised patient's condition whose families were studied participants, biosocial knowledge related to the members of family and part two which included CCFNI tool. The adapted CCFNI was translated into colloquial Arabic. Participant members of family were individually interviewed by the researcher. Members of family were required to answer each statement with strongly agree, agree, neutral, do not agree and strongly do not agree. The interview took approximately 45 to 60 minutes to be completed, and all interviews took place within the 72 hours' time frame of each patient's admission to the critical care unit. The nurses were approached and given the questionnaires to be filled in by themselves during handover, tea or lunch break.

Results: Generally, families ranked their knowledge, proximity and comfort needs higher in importance than the nurses. Also, the knowledge and assurance needs were ranked above the needs for support, comfort, and proximity by our participating nurses and members of family. Moreover, the mean scores of knowledge, proximity, support and comfort needs for members of family were significantly higher than these for nurses. Out of 35 needs of the members of family in the CCFNI, there were no significant differences between the mean scores of the nurses and those of the members of family in 10 individual needs. Results show that the nurses were correct in 10 out of 35 members of family' individual needs. The remaining mean scores from 25 individual needs showed significant differences between the nurses and actual family needs. Results show that did not meet all the specific family needs during the care of the critically ill patients. Results show that members of family scored significantly higher than nurses on 20 statements while, the nurses scored significantly higher than members of family on only 5 of the statements.

Conclusions: Families considered that knowledge then assurance was the most important needs. While nurses considered that assurance then knowledge were the most important needs which indicate that nurses underestimated the needs of the family and family need may be inaccurately evaluated by heath care team and almost unmet. Furthermore, Members of family in this study considered the needs that bring comfort and support as less in priority needs.
\end{abstract}

Key Words: Nurses, Families, Opinion, Priorities, Immediate, Patient's family needs

\footnotetext{
* Correspondence: Intessar Mohamed Ahmad; Email: abdelrahman.intessar@gmail.com; Address: Critical Care Nursing Department, Faculty of Nursing, Damanhour University, Damanhour, Egypt.
}

Published by Sciedu Press 


\section{INTRODUCTION}

Acute critical illness represents a crisis not just for the individual patient however conjointly for the members of the family. ${ }^{[1]}$ Moreover, the admission of the patient represents a sudden crisis allowing no time for its preparation. ${ }^{[2]}$ The sudden crisis triggers anxiety, fear and the feeling of hopelessness in the members of family. The critical care unit per say is frightening, and an unfamiliar environment for most families. ${ }^{[3]}$

Anxiety and fear are further magnified by financial concerns as well as the sudden disruption of the family homeostasis caused by the sudden role alterations stemming from the sudden crisis. Hence, care is also required by members of family. ${ }^{[4]}$ Previous studies indicate that patients, relatives have specific needs. ${ }^{[5,6]}$

Leske (1991) ${ }^{[7]}$ conducted a descriptive study of members of family, needs then, compared its results with those of Molter, ${ }^{[8]}$ these 45 needs statements identified by Molter randomly ranked. This instrument was then named the Critical Care Family Needs Inventory (CCFNI), which has been used in different studies. ${ }^{[9]}$

Researches on needs of families of intensive care patients have identified important needs and indicated that members of family of critically ill patients have specific needs. These have been identified as the need for knowledge regarding the patient's prognosis and management; reassurance that patient is receiving the ideal care and hope for recovery is sustained. Last, but not least, communication with the health team members. ${ }^{[7-10]}$

The support needs refers to the family's need for resources and support structures to help them cope with emotional distress and preserve their strength through their loved one's critical illness. The comfort needs, on the other hand, indicates the family's need for personal comfort and includes having access to adequate and comfortable waiting rooms, telephones, bathrooms, and good food. ${ }^{[11-13]}$

Time factor or lack of understanding of needs of members of family makes staff members direct all of their energy toward saving the life of the patient and the intention of giving family support is absent, the reality is that needs of members of family are often ignored or forgotten. Responsibilities of critical care nurses extend beyond the patients in ICU to include members of family of those patients. ${ }^{[1]}$

Nurses are a primary source for members of the family of the critically ill patient and they are in a perfect position to assist them to cope with patients' critical illness in an acceptable approach. ${ }^{[8]}$ For this reason, recognition of these needs by nursing personnel is important for the practice of holistic nursing care ${ }^{[9]}$ This study compare between intensive care nurses and patients' relatives' opinion about intensive care family needs.

\subsection{Aim of the study}

The aims of this study were:

(1) Ranking the immediate needs of members of family of critically ill patients and nurses.

(2) Comparing between nurses, and families, opinion regarding priorities of immediate patient's family needs using Critical Care Family Needs Inventory.

\subsection{Operational definitions}

The following terms were used for the purpose of this study:

- Immediate needs are the family needs within 72 hours period after the admission of their critically ill patient to the Critical Care Units.

- Members of family are spouses, the parents, the children (21 years of age or older) and the siblings.

\section{MATERIAL AND METHODS}

\subsection{Research design}

A descriptive research design was utilized to accomplish this study.

\subsection{Setting}

This study was conducted at the general ICU of Damanhour Medical Institute which has 15 beds, Damanhour chest hospital which has 7 beds and Itay Elbaroad General Hospital which has 11 beds. The three units have a total of 100 nurses. Damanhour Medical Institute and Itay Elbaroad ICUs were mixed units that admit adults with medical, surgical, trauma. While, Damanhour chest hospital intensive care unit was for patients with respiratory diseases only.

\subsection{Sample}

The study aimed all nurses and any one of family that were accessible at the time of the study. A total of 160 (80 nurses and 80 members of family of 80 critically ill patients) were involved in this study. The criteria of member of family selection were as follows: members of family which had to be 21 years of age or more, available during second and/or third day of hospitalization of the patient. Members of family were also selected regardless of gender and patient's diagnosis.

\subsection{Instrument}

The questionnaire that was used to collect data during this study consisted of 2 parts:

Part one: It comprised: 
a) The condition of the patients, whose families were study participants namely.

b) Biosocial knowledge related to the members of family.

Part two: Critical Care Family Needs Inventory tool (CCNI)

- Immediate family needs were identified using the Molter ${ }^{[8]}$ Critical Care Family Needs Inventory tool (CCNI) after its adaptation to the Egyptian's culture. This entailed the modification and/or omission of certain items. The tool was translated into Arabic by the researcher.

- It included 35 statements derived from the CCFNI. The 35 statements formed five 5 family need categories of: support 9 statements, knowledge 7 statements, proximity or closeness 6 statements, assurance 7 statements and comfort 6 statements.

- Every nurse and member of family was asked to indicate the level of agreement of each statement which is measured on a 5-point Likert scale as follows: 1 strongly disagree; 2 disagree; 3 neutral; 4 agree and 5 strongly agree.

\subsection{Procedures}

- The tool of the present study was adapted according to Egyptian culture. The adapted CCFNI (Critical Care Family Needs Inventory) was translated into colloquial Arabic. Accuracy and relevancy of the translated Arabic tool was established since, the tool was submitted to a Jury of 5 experts in Critical Care Nursing to assess clarity and content validity of the tool and all necessary changes were done accordingly.

- Reliability of the adapted Critical Care Family Needs Inventory was tested using Cronbach's Alpha test and results were 0.75 and 0.80 respectively.

- A pilot study was done on 8 nurses and 8 members of family (10\% of each group of the study sample) to test the clarity and applicability of the research tools and they were excluded from the study. Pilot study revealed that further modifications are not needed.

\subsection{Data collection}

- Participant members of family were individually interviewed by the researcher; one member of family per patient was interviewed. The interview took place at the entrance of the ICU, since there is no adjacent waiting room to the ICU for visitors. Visiting hours are from 3 to 4 o'clock p.m.

- Members of family: Females and males were required to answer each statement with strongly agree, agree, neutral, do not agree and strongly do not agree.
- The interview took approximately 45 to 60 minutes to be completed, and all interviews took within the 72 hours' time frame of each the patient's admission to the ICU.

- The nurses were approached and given the questionnaire to be filled in by themselves during tea or lunch break.

\subsection{Ethical consideration}

- An official letter from the college of nursing was delivered to the hospital authorities in the ICUs. Permission for data collection from the intensive care units was obtained from their hospital directors after providing an explanation of the aim of the study.

- Before conducting the study, informed consent was obtained and participants' members of family were provided with a verbal explanation of the purpose of the study and the name of the investigator.

\subsection{Data analysis}

The knowledge were coded and remodeled into coding sheets. The results were checked. Then, the knowledge was entered into the Statistical Package for Social Sciences (SPSS) version 17. Output drafts were checked against the revised coded knowledge for typewriting and writing system spelling mistakes. Finally, analysis and interpretation of knowledge were conducted.

The following statistical measures were used:

- Descriptive statistics including frequency and distribution were accustomed describe different characteristics.

- Quantitative data were summarized by the arithmetic mean and standard deviation.

- Ranking of items was done and comparison of means was done by student $t$-test. $p$ values less than or equal to .05 was considered to be statistically significant.

\section{RESULTS}

Table 1 demonstrates frequency distribution of members of family according to their socio-demographic characteristics. It can be noted that the mean age of the family members was $37.5 \pm 14.2$ years. Furthermore, members of family consisted of 49 males and 31 females. The educational background of $60 \%$ family members was a secondary school. Moreover, $50 \%$ of family members were technical workers. The majority $(71.3 \%)$ of members of family mentioned that they do not leave the hospital. 
Table 1. Frequency distribution of members of family's according to their socio-demographic characteristics

\begin{tabular}{|c|c|c|}
\hline \multirow{2}{*}{ Characteristics } & \multicolumn{2}{|l|}{ Frequency } \\
\hline & No. & $\%$ \\
\hline \multicolumn{3}{|l|}{ Age } \\
\hline$<25$ & 15 & 18.8 \\
\hline $25-$ & 20 & 25.0 \\
\hline $35-$ & 23 & 28.8 \\
\hline $45-55$ & 12 & 7.5 \\
\hline$\geq 55$ & 10 & 12.5 \\
\hline Min.-Max. & $17-70$ & \\
\hline Mean \pm SD & $37.5 \pm 14.2$ & \\
\hline \multicolumn{3}{|l|}{ Gender } \\
\hline Male & 49 & 61.3 \\
\hline Female & 31 & 38.7 \\
\hline \multicolumn{3}{|l|}{ Level of education } \\
\hline Read \& write & 14 & 17.5 \\
\hline Secondary & 48 & 60 \\
\hline University & 18 & 22.5 \\
\hline \multicolumn{3}{|l|}{ Occupation } \\
\hline Office clerks' workers & 19 & 23.7 \\
\hline Technical workers & 40 & 50 \\
\hline Student & 8 & 10 \\
\hline Others & 13 & 16.3 \\
\hline \multicolumn{3}{|l|}{ Leave the hospital } \\
\hline No & 57 & 71.3 \\
\hline Yes & 23 & 28.7 \\
\hline
\end{tabular}

Table 2 reveals frequency distribution of nurses according to their socio-demographic characteristics. It was found that the mean age of nurses was $26.2 \pm 4.41$ years and the majority of them $(77.5 \%)$ were females. Also, the educational level of the majority of nurses $86.2 \%$ were bachelor degree and $63.8 \%$ of them had less than 5 years of experience.

Table 3 shows a comparison between family and nurses according to the score of needs. Generally, it can be noted from this table that families ranked their knowledge, proximity and comfort needs higher in importance than the nurses. Also, the knowledge and assurance needs were ranked above the needs for support, comfort, and proximity by our participating nurses and family members. Moreover, the mean score of knowledge, proximity, support and comfort needs for family members were higher than that for nurses with significant difference ( $p$ value $=.001$ ) for each category.

Table 4 shows a comparison between the 2 studied groups according to family members' needs. Out of 35 needs for member of family in the CCFNI, there were no significant differences $(p>.05)$ between the mean scores of the nurses and those of the family members in 10 individual needs. So, nurses were correct in 10 out of 35 family members' needs.
The remaining scores of 25 individual needs showed significant differences $(p<.05)$ between the nurses and actual family needs. Results indicate that they did not meet all the specific needs of family during the care of critically ill patients. It can be noted that family members scored higher significantly $(p<.05)$ than nurses on 20 statements while the nurses scored higher significantly $(p<.05)$ than family members on only 5 of the statements, "Assured that there is hope", "Be sure that questions answered honestly", "Assured that patient's condition in progress", "Be sure that the best care is being given to the patient", "Be free to ventilate emotions".

Table 2. Frequency distribution of nurses according to their socio-demographic characteristics

\begin{tabular}{lll}
\hline \multirow{2}{*}{ Characteristics } & \multicolumn{2}{l}{ Frequency } \\
\cline { 2 - 3 } & No. & \% \\
\hline Age & & \\
$<25$ & 34 & 42.5 \\
$25-$ & 41 & 51.2 \\
$35 \geq 45$ & 5 & 6.3 \\
Min.-Max. & $22-44$ & \\
Mean \pm SD. & $26.20 \pm 4.41$ & \\
Gender & & \\
Male & 18 & 22.5 \\
Female & 62 & 77.5 \\
Level of education & & \\
Bachelor & 69 & 86.2 \\
Technical & 11 & 13.8 \\
Years of experience in nursing & & \\
$<5$ & 51 & 63.8 \\
$5-10$ & 20 & 25 \\
$\geq 10$ & 9 & 11.2 \\
\hline
\end{tabular}

Considering, assurance needs both of nurses and family members ranked the need "Be sure that the hospital personnel care about the patient" as the highest priority. The family members reported that "to feel that there is hope" as their second need. It was ranked higher than nurses did with significant difference $(p=.04)$. Nurses reported that "Be sure that the best care is being given to the patient" as their second need in priority and it was ranked lower than family members did with significant difference $(p=.00)$.

Family members considered "Be sure that questions answered honestly" as the lowest need of them while, nurses participant ranked this need statement higher in importance than family members with significant difference $(p=.02)$. Nurses ranked the need "Assured that will be reported about expected outcome" as the lowest need and it was ranked lower than family members did with significant difference $(p=.05)$. Nurses ranked "assured that patient's in progress" lower in importance than the family members did for this need statement with insignificant difference. 
Table 3. Comparison between family and nurses according to score of needs

\begin{tabular}{|c|c|c|c|c|c|c|}
\hline Needs & $\begin{array}{l}\text { Nurses } \\
\overline{\mathbf{x}} \pm \mathrm{SD} \\
\end{array}$ & Rank & $\begin{array}{l}\text { Family } \\
\overline{\mathbf{x}} \pm \text { SD }\end{array}$ & Rank & $t$ & $p$ \\
\hline $\begin{array}{l}\text { Assurance needs } \\
\text { Total score } \\
\% \text { score }\end{array}$ & $\begin{array}{l}31.08 \pm 2.52 \\
85.98 \pm 9.02\end{array}$ & 1 & $\begin{array}{l}31.10 \pm 3.13 \\
86.07 \pm 11.17\end{array}$ & 2 & 0.056 & .956 \\
\hline $\begin{array}{l}\text { Knowledge need } \\
\text { Total score } \\
\text { \% score }\end{array}$ & $\begin{array}{l}25.96 \pm 4.63 \\
67.72 \pm 16.53\end{array}$ & 2 & $\begin{array}{l}30.28 \pm 3.74 \\
83.13 \pm 13.36\end{array}$ & 1 & $6.480^{*}$ & $<.001 *$ \\
\hline $\begin{array}{l}\text { Proximity need } \\
\text { Total score } \\
\% \text { score }\end{array}$ & $\begin{array}{l}27.74 \pm 3.92 \\
74.06 \pm 14.01\end{array}$ & 4 & $\begin{array}{l}30.30 \pm 3.25 \\
83.21 \pm 11.60\end{array}$ & 3 & $4.501^{*}$ & $<.001^{*}$ \\
\hline $\begin{array}{l}\text { Support need } \\
\text { Total score } \\
\% \text { score }\end{array}$ & $\begin{array}{l}36.01 \pm 4.82 \\
75.03 \pm 13.39\end{array}$ & 3 & $\begin{array}{l}38.67 \pm 3.74 \\
82.43 \pm 10.38\end{array}$ & 5 & $3.905^{*}$ & $<.001^{*}$ \\
\hline $\begin{array}{l}\text { Comfort need } \\
\text { Total score } \\
\% \text { score }\end{array}$ & $\begin{array}{l}24.64 \pm 3.28 \\
77.66 \pm 13.69\end{array}$ & 5 & $\begin{array}{l}26.83 \pm 2.97 \\
86.77 \pm 12.36\end{array}$ & 4 & $4.420^{*}$ & $<.001^{*}$ \\
\hline
\end{tabular}

Note. $\overline{\mathrm{x}} \pm \mathrm{SD}: \mathrm{x}$ mean and SD standard deviation; $t, p: t$ and $p$ values for Student $t$-test. *: Statistically significant at $p \leq .05$.

Table 4. Comparison between the two studied groups according to members of family' needs

\begin{tabular}{|c|c|c|c|c|c|}
\hline Needs statement & $\begin{array}{l}\text { Nurses } \\
\overline{\mathbf{x}} \pm \text { SD }\end{array}$ & Rank & $\begin{array}{l}\text { Family } \\
\overline{\mathbf{x}} \pm \text { SD }\end{array}$ & Rank & $t(p)$ \\
\hline \multicolumn{6}{|l|}{ Assurance needs } \\
\hline - Assured that will be reported about expected outcome & $4.2 \pm 0.74$ & 7 & $4.4 \pm 0.63$ & 5 & $1.96\left(.05^{*}\right)$ \\
\hline - Assured that explanations given are understandable & $4.2 \pm 0.77$ & 6 & $4.6 \pm 0.53$ & 4 & $4.04 *(.00 *)$ \\
\hline - Assured that there is hope & $4.5 \pm 0.71$ & 5 & $4.3 \pm 0.86$ & 2 & $2.10 *(.04 *)$ \\
\hline - Be sure that questions answered honestly & $4.6 \pm 0.67$ & 4 & $4.3 \pm 0.61$ & 7 & $2.34 *(.02 *)$ \\
\hline - Assured when patient's conditioned in progress & $4.6 \pm 0.59$ & 3 & $4.5 \pm 0.55$ & 6 & $1.53(.13)$ \\
\hline - Be sure that the best care is being given to the patient & $4.8 \pm 0.37$ & 2 & $4.6 \pm 0.48$ & 3 & $2.93 *(.00 *)$ \\
\hline - Be sure that the hospital personnel care about the patient & $4.2 \pm 0.74$ & 1 & $4.4 \pm 0.63$ & 1 & $1.96(.05 *)$ \\
\hline \multicolumn{6}{|l|}{ Knowledge needs related to } \\
\hline - Person upon whom to call at hospital & $2.98 \pm 1.37$ & 7 & $3.81 \pm 1.29$ & 7 & $3.98 *(.00 *)$ \\
\hline - Staff members could give specific type of knowledge & $3.4 \pm 1.28$ & 6 & $4.39 \pm 0.70$ & 4 & $6.05 *(.00 *)$ \\
\hline - Patient treatment & $3.69 \pm 1.10$ & 5 & $4.45 \pm 0.59$ & 3 & $5.47 *(.00 *)$ \\
\hline - How to help with the patient's physical care & $3.85 \pm 1.08$ & 4 & $4.23 \pm 0.76$ & 5 & $2.54 *(.01 *)$ \\
\hline - Persons who give caring for the patient & $3.91 \pm 1.17$ & 3 & $4.20 \pm 1.79$ & 6 & $1.82(.07)$ \\
\hline - Things were done for the patient & $3.93 \pm 1.08$ & 2 & $4.56 \pm 0.50$ & 2 & $4.81 *(.00 *)$ \\
\hline - Obtain knowledge from doctors at least once daily & $4.21 \pm 0.87$ & 1 & $4.64 \pm 0.48$ & 1 & $3.83 *(.00 *)$ \\
\hline \multicolumn{6}{|l|}{ Proximity needs } \\
\hline - Interview with charge nurse every day & $3.51 \pm 1.11$ & 6 & $4.15 \pm 0.92$ & 5 & $3.96 *(.00 *)$ \\
\hline - Allowed frequent visits & $3.70 \pm 1.01$ & 5 & $4.33 \pm 0.87$ & 3 & $4.19 *(.00 *)$ \\
\hline - Informed about transfer plans while they are being made & $3.98 \pm 1.07$ & 4 & $4.23 \pm 0.89$ & 4 & $1.61(.11)$ \\
\hline - Visits changed for specific conditions & $4.03 \pm 1.15$ & 3 & $4.09 \pm 0.83$ & 6 & $0.40(.69)$ \\
\hline - Receiving telephone call about changes in the patient's condition & $4.14 \pm 0.82$ & 2 & $4.58 \pm 0.55$ & 1 & $3.96 *(.00 *)$ \\
\hline - Seeing patient repeatedly & $4.29 \pm 0.64$ & 1 & $4.46 \pm 0.59$ & 2 & $1.79(.080)$ \\
\hline \multicolumn{6}{|l|}{ Comfort needs availability of } \\
\hline - Telephone & $3.89 \pm 1.03$ & 6 & $4.41 \pm 0.71$ & 4 & $0.76 *(.00 *)$ \\
\hline - Feel secure about leaving hospital for a while & $3.91 \pm 1.02$ & 5 & $4.56 \pm 0.55$ & 2 & $5.02 *(.00 *)$ \\
\hline - Good food in the hospital & $3.98 \pm 1.20$ & 4 & $4.41 \pm 0.87$ & 5 & $2.64 *(.01 *)$ \\
\hline - Comfort furniture & $4.16 \pm 1.04$ & 3 & $4.46 \pm 0.55$ & 3 & $2.29 *(.02 *)$ \\
\hline - Bathroom & $4.33 \pm 0.88$ & 2 & $4.59 \pm 0.63$ & 1 & $2.17 *(.03 *)$ \\
\hline - Feeling passable by health team & $4.38 \pm 0.80$ & 1 & $4.39 \pm 0.82$ & 6 & $0.92(.10)$ \\
\hline \multicolumn{6}{|l|}{ Support needs } \\
\hline - Visiting hours start on time & $3.41 \pm 1.37$ & 9 & $4.34 \pm 0.89$ & 7 & $5.08 *(<.00 *)$ \\
\hline - Explanation of environment before going into unit & $3.53 \pm 1.31$ & 8 & $4.33 \pm 0.91$ & 8 & $4.48 *(<.00 *)$ \\
\hline - Someone be concerned with members of family's health & $3.94 \pm 1.02$ & 7 & $4.40 \pm 0.67$ & 4 & $3.39 *(.00 *)$ \\
\hline - Someone with family when visiting unit for first time & $3.96 \pm 0.92$ & 6 & $4.54 \pm 0.71$ & 1 & $4.42 *(<.00 *)$ \\
\hline - Freedom to ventilate emotions & $4.11 \pm 0.99$ & 5 & $3.41 \pm 1.03$ & 9 & $4.38 *(<.00 *)$ \\
\hline - Be alone with the patient at any time & $4.16 \pm 0.91$ & 4 & $4.36 \pm 0.70$ & 6 & $1.56(.12)$ \\
\hline - Financial support & $4.21 \pm 0.81$ & 3 & $4.43 \pm 0.81$ & 3 & $1.67(.10)$ \\
\hline - Discuss the possibility of the patient's dying & $4.34 \pm 0.87$ & 2 & $4.38 \pm 0.77$ & 5 & $0.29(.77)$ \\
\hline - What to do at the bedside & $4.35 \pm 0.75$ & 1 & $4.50 \pm 0.64$ & 2 & $1.37(.17)$ \\
\hline
\end{tabular}

Note. $\overline{\mathrm{x}} \pm$ SD: $\mathrm{x}$ mean and SD standard deviation; $t, p: t$ and $p$ values for Student $t$-test. *: Statistically significant at $p \leq .05$. 
In relation to knowledge needs, both of nurses and family members ranked the need "Knowledge related to things where done for the patient" as the first need. But, the mean score of family members was higher than the mean score of nurses with significant difference $(p=.00)$. Moreover, the need "to obtain knowledge from doctors at least once daily" was ranked as the second need by both of nurses and members of family. Furthermore, mean score of members of family was higher than mean score of nurses with significant difference $(p=.00)$. On the other hand, nurses and members of family ranked the need "Person upon whom to call at hospital" as the lowest need in importance while, the mean score of members of family was higher than that of nurses with significant difference $(p=.00)$.

As regards to proximity needs, the importance of the needs "seeing patient repeatedly" and "receiving telephone call about changes in the patient's" were ranked interchangeably between nurses and members of family. The need "seeing patient repeatedly" was ranked as the highest needs by nurses followed by the need "to be called at home about changes in the patient's condition". Contrary to that, "receiving telephone call about changes in the patient's" is considered the highest priority for members of family with its mean score by members of family was significantly higher than the mean score by nurses $(p=.00)$. Secondly, members of family ranked the need "receiving telephone call about changes in the patient's" and the mean score by members of family was higher than the mean score by nurses with no significant difference $(p=.08)$. The need "interview with charge nurses daily" was ranked as the lowest need by nurses. Moreover, "visits changed for specific conditions", was the lowest need for members of family.

As regards to comfort needs, the importance of the need "availability of bathroom" was ranked as the highest need by members of family. But, it was ranked as the second needs by nurses and the mean score of members of family was higher than mean score of nurses with significant difference ( $p=$ .03). The most important need which ranked by nurses was "feeling passable by health team". Members of family ranked the need "feel secure about leaving hospital for a while" as their second need. It was ranked higher than nurses did with significant difference $(p=.00)$.

As regards to support needs, nurses reported that the need "what to do at the bedside" as the most important need. But, members of family ranked it as the second need. Moreover the mean score of members of family was higher than mean score of nurses with no significant difference $(p=.17)$. The second needs for nurse was "discuss the possibility of the patient's death". However, members of family ranked the need "to have someone with family when visiting unit for first time" as the highest need and the mean score of members of family was higher than mean score of nurses with significant difference $(p=.00)$.

\section{Discussion}

This study aimed to compare between nurses, and families, opinion of family needs in critical care unit. Generally, families ranked their needs higher in importance than nurses did which indicate that nurses underestimated the needs of the family and family need may be inaccurately evaluated by heath care team. These results are against findings of similar studies. ${ }^{[14,15]}$ In these studies there have been similarities between nurses, and families rating of the individual family needs and need categories. It should be noted that nurses have a pivotal role to play in ensuring that family needs in the ICU are to be accurately identified. They are also in a position to ensure that the unmet needs of members of family of ICU patients are to be properly addressed.

This study revealed that the knowledge and assurance needs were ranked above the needs for support, comfort, and proximity by our participating nurses and members of family. This finding is congruent with those of other investigators. ${ }^{[16-18]}$ Moreover, it was against the finding of Reynolds and Prakink study. They found in their study that families of ICU patients ranked the assurance and proximity needs above the needs for knowledge, support, and comfort. ${ }^{[13]}$

Families ranked the knowledge needs higher in importance than the nurses did. This finding against a previous study which found their nurses' participant ranked the knowledge needs lower in importance than family did. ${ }^{[13]}$ Reynolds and Prakink found in their study that nurses and families gave the same rank position to the knowledge needs. According to Lam and Beaulieu have shown that the knowledge, assurance and proximity needs were ranked above support and comfort needs for the families of ICU admitted patients. ${ }^{[19]}$ Maxwell compared nurses and families' perceptions on the needs of family members. It was found that the needs for assurance and knowledge were ranked highest by both nurses and family participants. ${ }^{[9]}$

Davidson indicates that the knowledge needs are the primary need of members of family of a critically ill patient, which are commonly left unmet. ${ }^{[20]}$ The need for assurance is one of the family's primary needs to cope with a loved one's ICU admission. ${ }^{[6]}$ They should receive the assurance they feel is needed. If the members of family' needs for assurance, knowledge, comfort, support, and proximity are addressed by the health care team, family and patient's anxiety and stress are to be reduced. Meeting the needs of patient's families 
can also develop their trust in the health care team, increase their satisfaction with hospital care and help them cope with the stressful situation.

In this study, the comfort needs were the least important needs perceived by nurses and members of family. It is in line with the findings of previous studies. ${ }^{[12,13]}$ It could be related that the patient is the center of attention by members of family who are faced with a high level of emotional distress. As a result, members of family may give little attention to their personal needs for comfort. Although the needs for comfort were not the primary consideration for our family and nurse participants, this does not indicate that the needs for comfort are not a priority need for the family member of critically ill patients. It is incumbent on the health care team to accommodate members of family with the five basic needs of support, comfort, proximity, knowledge, and assurance.

Considering, assurance needs, both of nurses and members of family ranked high the need "be sure that the hospital personnel care about the patient". This is true, because it can possibly increase their hope and strengthen their trust in the medical team and it has been reported that the need for hope has been consistently emphasized by families during the critical illness of family members. However, it was interpreted as a hope that the sick relative will get better, and this hope can be transmitted to the families if the critical care nurse assures them that their sick relatives receiving the most effective potential care. This finding is in congruent with previous study ${ }^{[21]}$ in relation to members of family who ranked this need highly and considered it one of the top 3 needs.

Relatives considered "be sure that questions answered honestly" as the lowest need of them while, nurse participants ranked this need statement higher in importance than members of family. This finding is against Bijttebier et al.'s findings. ${ }^{[24]}$ While, members of family perceived the need "be sure that questions answered honestly" as their highest priority need. It may be related to those members of family of critically ill patients' experience of inadequate communication with doctors about the patient's medical diagnosis, treatment, and chance of recovery. Nurses ranked the need "be reported about expected outcome" as the lowest need. Following admission to an ICU, any knowledge about the patient's medical condition and prognosis, length of hospital stay, and the intensive care environment will cause a feeling of shock in the family. ${ }^{[22]}$ Also, this reason may explain why nurses ranked the need "assured that patient's condition in progress" lower in importance than the family did for this need statement.

Regarding knowledge needs, both of members of family and nurses ranked the needs "obtain knowledge from doctors at least once daily" and "things were done for the patient" as their 2 highest knowledge need. According to Auerbach et al, ${ }^{[23]}$ the most pressing need would like members of the family of patients within the critical care unit is to receive clear, apprehensible, and honest data regarding the patient's condition. This finding underlines the family's need for knowledge about the patient's progress at regular times and may be daily. It has been advanced that specifically informed about the care provided is needed by the members of family since; it assuages the feeling of guilt they may experience. The guilty feeling experienced is believed to be derived from the fact that members of the family are not directly participated in the care of the patient during his/her time of need.

In relation to proximity needs, nurses and family ranked the need "to be told about transfer plans while they are being made" high in importance. Moreover, the need "receiving telephone call about changes in the patient's condition" and "seeing patient repeatedly" was ranked as the highest needs by nurses and families. This finding is against that reported by Bijttebier. ${ }^{[22]}$ It can be explained by that most of our families do not leave hospital because they are always afraid miss anything could help their patient or do not follow changes in his/her condition and it makes them so tired and destress.

The need "interview with charge nurse every day" was ranked low by nurses and family. Moreover, "visits changed for specific conditions", ranked low by both nurses and family. This finding was at the same line with the current literature which show that nurses regard members of family' presence in critical care unit as an associate in nursing obstacle to nursing intervention and treatment. ${ }^{[24]}$

As regards to support needs, "explanation of environment before going into unit" was highly ranked in this study. This finding was in the same line with a previous study ${ }^{[21]}$ which reported that this need was reported by nurses as one of the 3 top needs. Nurses ranked "what to do at the bedside" as the highest priority it may be to decrease the members of family anxiety and gain their cooperation.

In relation to comfort need, the availability of comfort furniture in a waiting room near the patient is not considered an essential physical need, since in our culture people sit and/or squat anywhere when they have to face a long waiting period. This finding is in line with other study in which families in the critical area concentrate on the needs of their critically ill loved patient and regularly neglect their own physical and emotional needs. ${ }^{[8]}$

The members of family reported that the most important need is "availability of bathroom". This finding in the same 
line with the finding of Gundo's study. ${ }^{[12]}$ This study was conducted at public central hospital at Damanhour where members of the family taking care of patients lodge in the hospital and do not leave hospital which makes presence of bathroom is very essential. They ranked the need "feel secure about leaving hospital for a while" in the second place. Nurses ranked the need "feeling passable by health team" in the first place, this may be related to that fulfillment of this need will help the family to adapted well with their loved one.

\section{CONCLUSION AND RECOMMENDATIONS}

It can be concluded that families considered that knowledge then assurance the most important needs. On the other hand, nurses considered that assurance then knowledge as the most important needs indicating that nurses underestimated the needs of the family and family need may be inaccurately evaluated by heath care team and almost unmet. Furthermore, Members of family in this study thought of the needs that bring comfort and support as less in priority needs.

\section{Recommendations}

Based on the results of this study, the subsequent is recommended:
- Recommendations regarding education:

- Identification and exploration of important family needs of critically ill relatives should be placed within nursing students' curriculum.

- Recommendations regarding hospital services:

- Reviewing hospital policy regarding strategies that promote and guarantee provision of services that are in need to members of family of critically ill patients.

- Teaching and training programs should be performed to change the role of health care personnel from patient centered only to total patient care, then the staff should recognize the importance of helping relatives and it is a crucial part of holistic patient care.

- Recommendations regarding research:

- More studies are needed to gauge the impact of critically ill patient gender, condition and devices used on members of family, need.

\section{CONFlicts OF INTEREST Disclosure}

The author declares that there is no conflict of interest.

\section{REFERENCES}

[1] Kosco M, Warren NA. Critical care nurses' perceptions of family needs as met. Crit Care Nurs Q. 2000; 23: 60-7. https: //doi.org/10.1097/00002727-200008000-00008

[2] Romanini J, Daly J. Critical Care Nursing. Australian Perspectives. 1st ed. Sidney: W.B. Saunders Company. 1994; 38-41.

[3] Benz J. Critical Care Nursing. A Holistic Approach. 10th ed. Philadelphia, pa; London: Lippincott Williams \& Wilkins/Wolters Kluwer, Company. 2013; 19-25.

[4] Hudak C, Gallo B. Critical Care Nursing. A Holistic Approach. 11th Ed. Philadelphia: Wolters Kluwer Health Company. 2017: 24-31.

[5] Takman CA, Severinsson EI. The needs of significant others within intensive care-the perspectives of Swedish nurses and physicians. Intensive Crit Care Nurs. 2004; 20: 22-31. https ://doi .org/10 $.1016 /$ j.iccn. 2003.09.003

[6] Lee L, Lau y. Immediate needs of adult members of family of adult intensive care patients in Hong Kong. Journal of Clinical Nursing. 2003; 12: 490-500. https://doi.org/10.1046/j.1365-2702. 2003.00743.x

[7] Leske JS. Internal psychometric properties of the Critical Care Family Needs Inventory. Heart Lung. 1991; 20: 236-244.

[8] Molter NC. Needs of relatives of critically ill patients: a descriptive study. Heart Lung. 1979; 8: 332-339.

[9] Maxwell KE, Stuenkel D, Saylor C. Needs of members of family of critically ill patients: a comparison of nurse and family perceptions. Heart Lung. 2007; 36: 367-376. https ://doi.org/10.1016/j . hrtlng. 2007.02.005
[10] Takman C, Severinsson E. Comparing Norwegian nurses' and physicians' perceptions of the needs of significant others in intensive care units. J Clin Nurs. 2005; 14(5): 621-631. https : //doi .org/10.1 $111 / \mathrm{j} .1365-2702.2004 .01038$. $\mathrm{x}$

[11] Maxwell KE, Stuenkel D, Saylor C. Needs of Members of family of Critically Ill Patients: A Comparison of Nurse and Family Perceptions. Heart \& Lung. 2007; 36: 367-376. https : //doi .org/10.1 016/j.hrtlng.2007.02.005

[12] Gundo R. Comparison of Nurses' and Families' Perception of Family Needs in Intensive Care Unit at a Tertiary Public Sector Hospital [Master's thesis]. Johannesburg: University of the Witwatersand; 2010 .

[13] Reynold J, Prakinkit S. Needs of members of family of critically ill patients in cardiac care unit: A comparison of nurses and family perceptions in Thailand. Journal of Health Education. 2008; 31 : 53-66.

[14] Moggai F, Biagi S, Pompei V. The Needs of Relatives of Patients Admitted to Italian Critical Units: A Survey Comparing Relatives' and Nurses' Perceptions. The World of Critical Care Nursing. 2005; 4: 23-26.

[15] Hinkle JL, Fitzpatrick E. Needs of American Relatives of Intensive Care Patients: Perceptions of Relatives, Physicians and Nurses. Intensive and Critical Care Nursing. 2011; 27: 2218-2225.

[16] Chien WT, Chiu YL, Lam LW, et al. Effects of a needs-based education programme for family carers with a relative in an intensive care unit: A quasi-experimental study. Int J Nurs Stud. 2006; 43: 39-50. https://doi.org/10.1016/j.ijnurstu.2005.01.006 
[17] Omari FH. Perceived and unmet needs of adult Jordanian members of family of patients in ICUs. J Nurs Scholarsh. 2009; 41: 28-34. https://doi.org/10.1111/j.1547-5069.2009.01248.x

[18] Freitas KS, Kimura M, Ferreira KA. Members of family' needs at intensive care units: Comparative analysis between a public and a private hospital. Rev Lat-Am Enfermagem. 2007; 15: 84-92. https://doi.org/10.1590/S0104-11692007000100013

[19] Lam P, Beaulieu M. Experiences of families in the neurological ICU: A "bedside phenomenon". J Neurosci Nurs. 2004; 36: 142-55.

[20] Davidson JE. Family-centered care: Meeting the needs of patients' families and helping families adapt to critical illness. Crit Care Nurse. 2009; 29: 28-34. https://doi.org/10.4037/ccn2009611

[21] Gundo R, Bodole F, Lengu E, et al. Comparison of Nurses' and Families'Perception of Family Needs in Critical Care Unit at Referral
Hospitals in Malawi. Open Journal of Nursing. 2014; 4: 312-320. https://doi.org/10.4236/ojn.2014.44036

[22] Bijttebier P, Vanoost S, Delva D, et al. Needs of relatives of critical care patients: Perceptions of relatives, physicians and nurses. Intensive Care Med. 2001; 27: 160-5. https://doi .org/10.1007/s0 01340000750

[23] Auerbach SM, Kiesler DJ, Wartella J, et al. Optimism, satisfaction with needs met, interpersonal perceptions of the healthcare team, and emotional distress in patients' members of family during critical care hospitalization. Am J Crit Care. 2005; 14: 202-10.

[24] Berti D, Ferdinande P, Moons P. Beliefs and Attitudes of Intensive Care Nurses toward Visits and Open Visiting Policy. Intensive Care Medicine. 2007; 33: 1060-1065. https://doi.org/10.1007/s0 0134-007-0599-x 